Authors' opinions

\title{
Physical activity as a prescription for the children with cerebral palsy
}

\author{
Arghavan Shariat ${ }^{1}$, Ardalan Shariat ${ }^{2}$, Ahmad Abedi ${ }^{1}$, Shamsul Bahri Mohd Tamrin ${ }^{2}$ \\ ${ }^{1}$ Isfahan University, Isfahan, Iran \\ ${ }^{2}$ University Putra Malaysia, Serdang, Malaysia
}

Received 7 November 2013, Accepted 2 December 2013

(C) 2013, Shariat A., Shariat A., Abedi A., Bahri M.T.S

(C) 2013, Russian Open Medical Journal

\begin{abstract}
After so many years devoted to practicing medicine as children physiotherapists, the therapists finally found the importance of balance training exercises in children who suffer from cerebral palsy. It is only through controlling balance that we can achieve improvement in body movement and position that will culminate into performance independence in a child. Formerly, working over controlling balance in cerebral palsy children has been very difficult, because contracture and spasticity did not let us to have an effective balance training exercise. In this respect, we have summarized the results of previous authors that specify the level of effectiveness of exercise therapy. The results of different studies showed that level of effectiveness of exercise therapy on alleviating the symptoms of spastic cerebral palsy is average in accordance with Cohen's effect size Interpretation table.
\end{abstract}

Keywords: physical therapy, spastic cerebral palsy, children

Cite as Shariat A, Shariat A, Abedi A, Bahri MTS. Physical activity as a prescription for the children with cerebral palsy. Russian Open Medical Journal 2014; 3 : 0108.

Correspondence to Arghavan Shariat. Tel: +98-9130112748. E-mail: ashariat@rocketmail.com

\section{Introduction}

Cerebral palsy (PC) is the nervous-muscle system disorder that seems to occurs follow damage or failure in the cerebrospinal nerve fibers segment, before or after pregnancy in early years [1]. The $\mathrm{CP}$ is as a result of non- progressive damage to the developing brain that include heterogeneous Epilepsy which is nervousnessclinically signs of this disease [2]. And also CP is a neurologicalmotor disorder with a range of underlying common causes in childhood [3]. In another definition, cerebral palsy can be defined as a series of permanent and non-progressive motor disorder that causes stiffness in motion or mentally. motor disorders of cerebral palsy are often associated with sensory - perceptual - cognitive, communication and behavior disorders, epilepsy and secondary musculoskeletal problems [3].

Movement disability is the original problem in Cerebral palsy and clinical cerebral palsy is classified as Spastic, Atetoid and Hyponoic which all of them arose from impaired growth and development of motion center of the brain [4]. The limitation of motion center performance in children with cerebral palsy that is the most common physical disability in them $[5,6]$. Occupational therapy in children with cerebral palsy is done to prevent muscle tissue stiffness, treating muscle disorders and reducing motor and sensory deficits of their body [3]. Currently, several methods used to treat children with cerebral palsy that show hopefully effects in improving motion center and physical and application activities, that in this regard, treatment of neural development method [7] and method of sensory-motor integration therapy [8] pioneered in serving and treatment of PC children in the field of occupational therapy [9].
Rate of this disease outbreak is 2 in 100 births [10]. Nearly half of the patients with cerebral palsy are spastic patient [2]. Patients with spastic cerebral palsy due to lack of physical activity and mobility limitation during exercise and occupational therapy must absorb more oxygen, but nevertheless have lower motor efficiency, mobility and physical capacity compared with healthy subjects. Research showed that the maximum amount of Energy consumption for walking on a treadmill in children with spastic is three times of the normal children $[11,12]$. Some researches also showed that exercise and physical therapy and rehabilitation in a clinical-physical course, leads to improvement in physical and physiological parameters [13]. it can be effective on the secretion of endocrine hormones [14], and also it can be effective for these patients [9].

Since cerebral palsy is known with reduced physical performance and capabilities, delayed in motor site development (in the brain), and impairment in the ability of the body's form and strength of muscles and movement patterns $[12,15]$ in children with $\mathrm{CP}$, to facilitate improvement database development and independence movements in motor skills, and also enhance their mobility, self-care, play and do fun activities, leisure time, physical and occupational therapy are needed [8]. Aki et al. assessed occupational therapy for children with $\mathrm{CP}$ and provided this point that doing occupational therapy, a significant improvement in motor function and also in their social relationships was received [10]. Tieman and colleagues have studied physical ability and motor function in children with $\mathrm{CP}$ and provided documented evidence of the differences between this and motor function in children with CP capabilities similar to those of healthy children before and after the treatment [16]. 
Table 1. Table of discriminating examining variables used in the study

\begin{tabular}{|c|c|c|c|}
\hline Research & Independent 1 & Independent 2 & Dependent 1 \\
\hline 1 & Before exercise therapy & After exercise therapy & The balance in function of children with spastic $\mathrm{CP}$ \\
\hline 2 & Regular rehabilitation and exercise program & & $\begin{array}{l}\text { Motor efficiency and increase aerobic exercise capacity in children } \\
\text { with } \mathrm{CP}\end{array}$ \\
\hline 3 & Aimed exercises (sit - walk) & & Strength in motor function in children with spastic $\mathrm{CP}$ \\
\hline 4 & Exercise therapy in children with cerebral palsy & & Distribution of body weight on the toe and heel \\
\hline 5 & Therapeutic effects of exercise & & Improve dynamic balance in children with spastic CP \\
\hline 6 & Exercise therapy & & Energy consumption and metabolic effects in children with spastic $\mathrm{CP}$ \\
\hline
\end{tabular}

Table 2. Meta-analysis results of the effectiveness of exercise therapy on children with spastic cerebral palsy

\begin{tabular}{ccccr}
\hline $\begin{array}{c}\text { Number of } \\
\text { research }\end{array}$ & $r$ & $d$ Cohen & $Z$ & $P$ \\
\hline 1 & 0.97 & 7.98 & 3.090 & 0.001 \\
2 & 0.42 & 0.93 & 1.645 & $<0.05$ \\
3 & 0.83 & 2.98 & 3.719 & $<0.001$ \\
4 & 0.52 & 1.22 & 1.645 & $<0.05$ \\
5 & 0.42 & 0.93 & 1.645 & $<0.05$ \\
6 & 0.42 & 0.93 & 1.645 & $<0.05$ \\
\hline
\end{tabular}

Jansen and colleagues investigated the involvement of parents of children with CP when therapy and showed that if children who have no ability to have a physical or mental disability do occupational therapy by their parent could make better progress in their daily performance [9]. Due to the discrepancy in the results of the investigation into the effectiveness of exercise therapy on children with $\mathrm{CP}$, it seems that conducting a previous authors' opinions method of making a real impact of physical therapy help to children with spastic cerebral palsy and the effectiveness of exercise therapy on reducing children with spastic cerebral palsy will be determined.

In fact, this study, sought to answer the question of whether exercise therapy is effective on children with spastic cerebral palsy? We investigate on the combined effect size of various researches rather than a specific hypothesis.

\section{Material and Methods}

In this study, meta-analytic methods are used based on the purpose of research. The basic tenet of meta-analysis is calculating effect sizes for individual studies and turning them into a common (generic) matrix and then combining them to achieve the mean effect [17]. Population of study were thesis, essays and sketches research that has been done on the effects of exercise therapy on children with spastic cerebral palsy and have a good sample size and in terms of methodology (theory building, research method, population, sample size, sampling methods, measuring instrument, the validity and reliability of the measuring instruments, statistical theory, statistical analysis and being correct statistical calculation) mentioned researches have qualified. In this study, 22 articles that fit inclusion criteria have been used.

In other words, the fit inclusion criteria for the meta-analysis were:

i) To qualify in terms of methodology (theory building, research method, sample size, sampling, measurement instruments, reliability and validity of measurement instrument, statistical theory, statistical analysis and being correct statistical calculation);

ii) The subject of research should be treatment of children with spastic cerebral palsy;

iii) Investigations were carried out on an experimental basis;

iv) Investigation was done in a group study (it was not base on case or single test).

Exclusion criteria were studies that had not methodological conditions or have been doing in case review, correlation and descriptive method.

\section{Check list of analysis content}

This checklist is used for choosing thesis and research papers for list of inclusion criteria and extracting the necessary information to conduct a meta-analysis and check list included the following factors: "title of conducted research on the effect of exercise therapy on children with spastic cerebral palsy", "complete characteristics of anchors", "year of conducting the study", means hypothesis "validity" and "reliability" of means of the statistical data collection, sample size and significance level of used test in this study. Table 1 has been discussed to separate investigating the mentioned variable.

\section{Research Findings}

In this section, based on provided data in the report of each research, calculating the effect size of exercise therapy on children with spastic cerebral palsy is discussed. Therefore, we must individually calculate what is called an effect size for each study. Effect sizes represent standardized difference between the means of the control and experimental groups [18] and in order to calculate It, the mean difference ratio between the experimental and control groups on the merger's variance of the total scores should be obtained.

Computational methods of meta-analysis is performed based on the meta-Cohen [19]. In this meta-analysis four basic steps should be taken: Identification, selection, abstraction and analysis (Table 2). Results shows the size effect of exercise therapy on children with spastic cerebral palsy is obtained 59/0 that based on the table Cohen $d$ is at the intermediate level. According to information of conducted studies, each one considered a different treatment pattern or patterns as the independent variable and a separate concept is considered as the dependent variable.

\section{Discussion}

By putting together the results of a study conducted on a sample of a community, the different subjects are examined, such as findings in the communities like our society that is more 
diverse, is more important, because this diverse is combined with many more differences. Inevitably we should have many details information about different examples of this community to by consolidate this information gain the similarities and can properly treat with differences [20]. Given that the effect sizes in this metaanalysis obtained 59/0, we can say that the effect of exercise therapy for CP spastic symptoms in children with spastic cerebral palsy is moderate. Based on the findings of this meta-analysis therapists can choose appropriate treatment to decrease CP symptoms to obtain better and more reliable results [11, 21, 22]. It is proposed that treatment method of nerve development and sensory-motor integration therapy be included in daily programs of these children from practitioners because of being pioneer in serve and treatment of children [11, 23, 24].

According to the previous researches in this area, it is estimated that effects of a rehabilitation and exercise therapy with high standards and effectiveness for 3 times a week for 3 months maybe is in order to enhancing motor performance and increasing the ability of aerobic exercise and registering body-cardiovascular changes in children CP comparing with healthy children $[25,26]$.

\section{Conclusion}

These studies typically consider that future developments in increasing during birth care minimize the effects and damages of this stage of birth on the baby's brain and incidence of CP; and researches should Be performed in order to development and biological progress and detection of CP causes in infants $[27,28]$.

As a practical suggestion for further researches, it is suggested to examine the effects of specific kinds of training on stability [29] of this population and also assess the effectiveness of new methods of therapy such as Poetry therapy and music therapy [30].

\section{Acknowlegment}

Hereby, the authors of this article wish to express their special thanks to Isfahan University and University Putra Malaysia.

Conflict of interest: none declared

\section{References}

1. Krigger KW. Cerebral palsy: an overview. Am Fam Physician 2006; 73: 91-100. (PMID: 16417071)

2. Hadjipanayis A, Hadjichristodoulou C, Youroukos S. Epilepsy in patients with cerebral palsy. Dev Med Child Neurol 1997; 39: 659-663.

3. Shamsoddin A. Comparison between the effect of neurodevelopmental treatment and sensory integration therapy on gross motor function in children with cerebral palsy. Iran J Child Neurol 2010; 4: 31-38.

4. Ellenberg $\mathrm{JH}$, Nelson KB. The association of cerebral palsy with birth asphyxia: a definitional quagmire. Dev Med Child Neurol 2013; 55(3): 210-216. (doi: 10.1111/dmcn.12016) (PMID: 23121164)

5. Champagne $D$, Dugas $C$. Improving gross motor function and postural control with hippotherapy in children with Down syndrome: Case reports. Physiother Theory Pract 2010; 26(8): 564-571. (doi: 10.3109/09593981003623659) (PMID: 20673078)

6. Whalen $\mathrm{CN}$, Case-Smith J. Therapeutic effects of horseback riding therapy on gross motor function in children with cerebral palsy: a systematic review. Phys Occup Ther Pediatr 2012; 32(3): 229-242. (PMID: 22122355) (doi: 10.3109/01942638.2011.619251)

7. McGibbon NH, Andrade CK, Widener G, Cintas HL. Effect of an equinemovement therapy program on gait, energy expenditure, and motor function in children with spastic cerebral palsy: a pilot study. Dev Med Child Neurol 1998; 40: 754-762. (PMID: 9881805)

8. Van den Hecke A, Malghem C, Renders A, Detrembleur C, Palumbo S, Lejeune TM. Mechanical work, energetic cost, and gait efficiency in children with cerebral palsy. J Pediatr Orthop 2007; 27: 643-647. (PMID: 17717464) (doi: 10.1097/BPO.0b013e318093f4c3)

9. Jansen LMC, Ketelaar M, Vermeer A. Parental experience of participation in physical therapy for children with physical disabilities. Dev Med Child Neurol 2003; 45: 58-69. (PMID: 12549757) (doi: 10.1111/j.1469-8749.2003.tb00861.x)

10. Ahl LE, Johansson E, Granat T, Carlberg EB. Functional therapy for children with cerebral palsy: an ecological approach. Dev Med Child Neurol 2005; 47: 613-619. (doi: 10.1111/j.1469-8749.2005.tb01213.x) (PMID: 16138669)

11. Levitt S, Pickering D. Treatment of cerebral palsy and motor delay. Wiley-Blackwell, 2010.

12. Shamir M, Dickstein R, Tirosh E. Intensive intermittent physical therapy in infants with cerebral palsy: a randomized controlled pilot study. Isr Med Assoc J 2012; 14(12): 737-741. (PMID: 23393711)

13. Shariat A, Tamrin SBM, Danaee M, Karimi $H$. The responses of white blood cells to weight loss among young male judoists. Russian Open Medical Journal 2013; 2: 0311.

14. Shariat A, Kargarfard M, Mohd Tamrin SB, Danaee M, Karimi H. Strength-training and biological rhythm of male sex hormone among judoists. Biological Rhythm Research 2014; 45: 1-14.

15. Dodd KJ, Taylor NF, Damiano DL. A systematic review of the effectiveness of strength-training programs for people with cerebral palsy. Arch Phys Med Rehabil 2002; 83: 1157-1164. (PMID: 12161840) (doi: 10.1053/apmr.2002.34286)

16. Tieman BL, Palisano RJ, Gracely EJ, Rosenbaum PL. Research report gross motor capability and performance of mobility in children with cerebral palsy: a comparison across home, school, and outdoors. J Am Phys Ther Assoc 2004; 84: 419-429. (PMID: 15113275)

17. Farrokhi F, Abedi N, Beyene J, Kurdyak P, Jassal SV. Association between depression and mortality in patients receiving long-term dialysis: a systematic review and meta-analysis. Am J Kidney Dis. 2013 Oct 31. (doi: 10.1053/j.ajkd.2013.08.024)

18. Yarnold PR. Maximum-accuracy multiple regression analysis: influence of registration on overall satisfaction ratings of emergency room patients. Optim Data Anal 2013; 2: 72-74.

19. Cohen L, Manion L, Morrison K. Research methods in education. Routledge, 2011.

20. Sadeghi $H$, Shariat A, Asadmanesh E, Mosavat $M$. The effects of core stability exercise on the dynamic balance of volleyball players. Int $J$ Appl Exerc Physiol 2013; 2(2): 1-10.

21. Flanagan A, Krzak J, Peer M, Johnson P, Urban M. Evaluation of shortterm intensive orthotic garment use in children who have cerebral palsy. Pediatr Phys Ther 2009; 21(2): 201-204. (PMID: 19440130) (doi: 10.1097/PEP.0b013e3181a347ab)

22. Scholtes VA, Becher JG, Comuth A, Dekkers H, van Dijk L, Dallmeijer AJ. Effectiveness of functional progressive resistance exercise strength training on muscle strength and mobility in children with cerebral palsy: a randomized controlled trial. Dev Med Child Neurol 2010; 52(6): e107-e113. (doi: 10.1111/j.1469-8749.2009.03604.x) (PMID: 20132136)

23. Ayers ME. Neurofeedback for cerebral palsy. Taylor \& Francis, 2004.

24. Aghaei M, Golgaryan MA, Asadollahi A. Investigating Internal Controls in Investment Companies from the Viewpoint of Independent Auditors. J Basic Appl Sci Res 2013; 3(4): 810-814.

25. Chiarello LA, Palisano RJ, Bartlett DJ, McCoy SW. A multivariate model of determinants of change in gross-motor abilities and engagement in self-care and play of young children with cerebral palsy. Phys Occup Ther Pediatr 2011; 31(2): 150-168. (PMID: 20964514) (doi: 10.3109/01942638.2010.525601) 
26. Van Wely L, Becher J, Reinders-Messelink H, Lindeman E, Verschuren O, Verheijden J, et al. LEARN 2 MOVE 7-12 years: a randomized controlled trial on the effects of a physical activity stimulation program in children with cerebral palsy. BMC Pediatr 2010; 10(1): 77. (doi: 10.1186/1471-2431-10-77)

27. Hidecker MJC, Paneth N, Rosenbaum PL, Kent RD, Lillie J, Eulenberg JB, et al. Developing and validating the Communication Function Classification System for individuals with cerebral palsy. Dev Med Child Neurol 2011; 53(8): 704-710. (PMID: 21707596) (PMCID: PMC3130799) (doi: 10.1111/j.1469-8749.2011.03996.x)

28. Holt R, Weightman A, Gallagher J, Preston N, Levesley M, MonWilliams $\mathrm{M}$, et al. A system in the wild: deploying a two player arm rehabilitation system for children with cerebral palsy in a school environment. J Usability Stud 2013; 8(4): 111-126.

29. Sadeghi H, Shariat A, Asadmanesh E, Mosavat M. The Effects of core stability Exercise on the dynamic balance of volleyball players. International Journal of Applied Exercise Physiology 2013; 2(2): 1-10.

30. Jabarouti R, Shariat A, Shariat A. Effect of Persian classic poetry on the level of stress hormone in retired academicians. Journal of Poetry Therapy 2013; 27(1): 1-9.

Authors:

Arghavan Shariat - Ms.C, Faculty of Psychology and Educational Science, Isfahan University, Isfahan, Iran;

Ardalan Shariat - PhD student, Department of Physical Education and Sport Sciences, Faculty of Educational Studies, Uiversity Putra Malaysia, Serdang, Malaysia;

Ahmad Abedi - Professor, Faculty of Psychology and Educational Science, Isfahan University, Isfahan, Iran;

Shamsul Bahri Mohd Tamrin - Associate Professor, Department of Environment and Occupational Health, Faculty of Medicine and Health Science, Uiversity Putra Malaysia, Serdang, Malaysia. 